Send your letters to the editor, British Dental Journal, 64 Wimpole Street, London W1G 8YS E-ail bdj@bda dentistry.org.uk

Priority will be given to letters less than 500 words long. Authors must sign the letter, which may be edited for reasons of space

\section{Multi-speciality agreement needed}

Sir,-We note with interest recent correspondence within the BDJ and British Journal of Oral \&t Maxillofacial Surgery regarding the management of anticoagulated patients undergoing dentoalveolar surgery. We are analysing data from national studies including an audit of current practice in 92 maxillofacial units and a survey of recommendations from 153 haematology units. There seems to be a continuing lack of consensus of advice offered regarding the management of these patients. In July 2001 the NorthWest Medicine Information centre produced guidelines that were BDA endorsed. The DPF have subsequently published guidelines that supersede the evidence based UKMI information. The DPF recommends a lower INR of 3.0 and also alters the type and extent of surgery carried out. We are interested to know the reasons behind these changes.

There are clearly different opinions between the specialities involved - oral and maxillofacial, primary dental care and haematology. Do the current DPF recommendations, which are targeted at primary care, extend to secondary care maxillofacial units? Our national study suggests that the majority of maxillofacial units are actually prepared to operate at INRs $>$ 3.0. In a pilot study of 45 hospitals the recommended operative INRs of the maxillofacial surgeons and the hematologists only concurred in one third of cases with the haematologists advocating much lower INRs. We feel that further concise guidance is required but this must have multi-specialty agreement. R. Kerr, P. Blacklock Devon

\section{Simon Carruthers, Chairman of the BDA Formulary Committee responds:}

The BDA Formulary Committee stands by the advice contained in the Dental Practitioners' Formulary ${ }^{1}$, and reiterated previously in this journal ${ }^{2}$. The recommended threshold INR of 3.0 was set after careful consideration and was chosen in order to give a wide safety margin for GDPs. What happens in a hospital setting is, we would suggest, not directly relevant to the issue of what advice should be issued to practitioners in primary care, given that hospital colleagues have wide access to help and advice at a moment's notice should any problem occur.

1. Dental Practitioners' Formulary 2002-2004. London: BDA, BMA, RPSGB. pp. D8, 117-119.

2. BrDent J 2003; 194: 530 and 195: 2

doi: 10.1038/sj.bdj.4810418

This correspondence is now closed

\section{Tooth notation minus confusion}

Sir,- I laughed when I read G. Belok's letter (BDJ 2003, 194: 646), because it reminded me of one of my first dental anatomy lectures, about seven years back now. After going over the Palmer and FDI systems of tooth notation, the lecturer briefly outlined the US method. However, he promptly stated '... but forget about that one, because it doesn't mean anything! The codes do not tell you anything about the teeth'. I quite agree. The Palmer system has its faults, but at least a layperson can understand and use it within minutes. As for ease of use on a computer, I think modern machines might just be able to cope with an alphanumeric code of three characters. The FDI system works perfectly on a computer and is still far more meaningful than the US notation. Credit is due to the $B D J$ for updating recently to a sensible, easy-to-use system.

R. Cresswell

Wolverhampton

doi: 10.1038/sj.bdj.4810419

\section{Nurse's reunion}

Sir,- I am hoping to make contact with past colleagues from 1982-83 when we were student dental nurses at King's College Dental Hospital. I am trying to arrange a 20 year reunion sometime this year but time is running out. Those who may know of anyone in my year can contact Claire Hughes (formerly Hopper), 17 Heather Drive, Lowry Hill Carlisle, Cumbria CA3 OES or e-mail dunnyon@thewold.freeserve.co.uk C. Hughes

Cumbria doi: 10.1038/sj.bdj.4810420

\section{Prolonged paraesthesia}

Sir,- I read with interest recently a letter to the editor of the British Journal of Oral \& Maxillofacial Surgery ${ }^{1}$ on the apparent relationship between inferior alveolar nerve block injections with articaine and an apparently increased incidence of prolonged dysaesthesia. At the Leeds Dental Institute we too have observed an apparent increase in the incidence of prolonged dysaesthesia following inferior alveolar nerve block injection in the last few years (seven cases), all but one of which have been associated with articaine administration. Your readers may wish to refer to a paper by D A Haas and D Lennon ${ }^{2}$ which showed a dramatic rise in reported incidents of dysaesthesia following local anaesthetic administration in Ontario, coincident with the introduction of articaine to dental practice in that province.

It would seem that there is sufficient evidence to urge some caution in the widespread use of articaine as a local anaesthetic alternative to lignocaine. A widespread survey of the relationship of prolonged dysaesthesia to particular drug choices would seem justified to clarify this apparent adverse effect.

J. Pedlar

Leeds

doi: 10.1038/sj.bdj.4810421

1. van Eden S P, Patel M F. Prolonged Paraesthesia Following Inferior Alveolar Nerve Block Using Articaine. Br J Oral Maxillofac Surg 2002; 40: 519-520

2. Haas D A, Lennon D. A 21 Year Retrospective Study of Reports of Paraesthesia Following Local Anaesthetic Administration. J Can Dent Assoc 1995; 61: 319-330

This letter was originally published in BDJ 2003, 194: 181 with an error in the number of cases. It has been reprinted here with the correct number of cases. We apologise for any misunderstanding. 